Revista Brasileira do Esporte Coletivo - v. 2. n. 2. 2018.

\title{
OS JOGOS LÚDICOS NA INICIAÇÃO DO VOLEIBOL PARA CRIANÇAS DE 8 A 10 ANOS
} LUDICIDADE E VOLEIBOL

\author{
${ }^{1,2}$ Marcelo Francisco Rodrigues, ${ }^{1}$ Anderson Colla, ${ }^{1}$ Leandro André Rodrigues do Prado, ${ }^{1}$ Rosana \\ Domingues dos Reis de Lazari, ${ }^{2,3,4}$ Henrique Miguel.
}

\section{RESUMO}

Introdução: O voleibol é um esporte de alta complexidade e imprevisibilidade, contendo habilidades motoras peculiares. No início da aprendizagem do voleibol, o professor deve propor aos alunos, brincadeiras lúdicas direcionadas para prática esportiva, respeitando o desenvolvimento motor da criança, seus limites, de acordo com a sua faixa etária. Objetivo: O objetivo desse estudo foi avaliar os benefícios encontrados nos jogos lúdicos na iniciação do voleibol para crianças de 8 a 10 anos. Método: Este trabalho foi realizado a partir de uma revisão de literatura, utilizando as seguintes bases de dados: Scielo, Lilacs, Bireme, SBU, Sportdiscus e livros publicados, com as seguintes palavras chave: voleibol, pedagogia do esporte e iniciação esportiva. Resultados e discussão: Dentre os estudos analisados, podemos destacar a sistematização do voleibol a partir de suas determinantes técnicas para a execução do jogo, permeando os métodos de ensino a partir da repetição do movimento/fundamento. Conclusão: Conclui-se que a aprendizagem do voleibol a partir do jogo mostra-se uma saída importante como possibilidade metodológica, pois, proporciona ao aluno as sensações contidas no jogo formal, e para criança que inicia neste esporte é imprescindível.

Palavras Chaves: voleibol, pedagogia do esporte, iniciação esportiva.

\section{THE LEVEL GAMES IN VOLLEYBALL INITIATION FOR CHILDREN OF 8 TO 10 YEARS LUDICITY AND VOLLEYBALL}

\section{ABSTRACT}

Introduction: Volleyball is a sport of high complexity and unpredictability, containing peculiar motor skills. At the beginning of learning volleyball, the teacher should propose to the students, playful games directed to sports practice, respecting the motor development of the child, its limits, according to its age group. Objective: The objective of this study was to evaluate the benefits found in recreational games in the beginning of volleyball for children aged 8 to 10 years. Method: This work was carried out from a literature review, using the following databases: Scielo, Lilacs, Bireme, SBU, Sportdiscus and published books with the following keywords: volleyball, sports pedagogy and sports initiation. Results and discussion: Among the analyzed studies, we can highlight the systematization of volleyball from its technical determinants for the execution of the game, permeating the teaching methods from the repetition of the movement / foundation. Conclusion: It is concluded that learning volleyball from the game is an important way out as a methodological possibility, since it provides the student with the feelings contained in the formal game, and for children who start in this sport is essential.

Key words: volleyball, sport pedagogy, sports initiation.

\footnotetext{
${ }^{1}$ Departamento de Educação Física - UNIMOGI, ${ }^{2}$ Departamento de Educação Física - UNIPINHAL, ${ }^{3}$ Departamento de Educação Física - FEUC, ${ }^{4}$ Departamento de Educação Física - UNIFENAS.

Endereço: UNIMOGI: Avenida Padre Jaime, 2.600. Jardim Serra Dourada, Mogi Guaçu/SP. Tel (19) 3831- 3080

E-mail: marcelo.edufisica@hotmail.com, marcelo.edufisica@hotmail.com, marcelo.edufisica@hotmail.com,marcelo.edufisica@hotmail.com, prhmiguel@gmail.com
} 


\section{INTRODUÇÃO}

Atualmente a metodologia de ensino nos esportes tem alcançado grandes avanços graças ao grande número de pesquisas científicas no gênero. O voleibol necessita que seus praticantes tenham domínio das capacidades, saibam reagir perante a dinâmica do jogo e eficácia na tomada de decisão.

O voleibol é uma modalidade de alta complexidade e imprevisibilidade, sendo indispensável que na sua fase de aprendizagem, se estimule todas as capacidades e habilidades motoras exigidas, as quais são dependentes das capacidades coordenativas de adaptação, de estabilização, ritmo, reação e orientação (REGA et al., 2009). Devido sua complexidade, é fundamental conhecer e dominar as habilidades básicas exigidas pelo esporte. Habilidades como: movimentos rápidos com precisão, domínio corporal, e ter capacidades de grande flexibilidade de membros superiores, força muscular de membros inferiores (REGA et al., 2009).

O esporte é um fenômeno social e cultural, e um facilitador na educação das crianças. Reverdito e Scaglia (2009), afirmam que, o esporte envolve a formação do cidadão, desenvolve a capacidade de solucionar problemas, desperta a curiosidade para ser um individuo crítico, e ainda utiliza seus conhecimentos em benefício próprio e social.

Seguindo neste conceito, é relevante que na iniciação esportiva deve-se adaptar o desporto a criança e não a criança ao desporto, sendo necessário elaborar métodos pedagógicos de acordo com a necessidade da faixa etária trabalhada, realizando-a de maneira lúdica (GALATTI et al ,2008). O universo lúdico pode ser uma saída para que as crianças vivenciem e explorem todo seu potencial de movimento, visto que a prática prazerosa e alegre pode ser um elemento transformador do educando (MELO et al., 2010).

A iniciação esportiva tem sido tema de abrangentes investigações, e com este trabalho, temos o escopo de analisar a importância do lúdico na formação educacional e esportiva de crianças de 8 a 10 anos no processo de iniciação do voleibol. Analisando o quanto à participação de atividades lúdicas pode contribuir para o desenvolvimento da criança. No entanto não foram encontrados trabalhos referentes à idade supracitada na iniciação a partir de jogos no voleibol. Sendo assim, o objetivo deste trabalho é, de uma maneira global, verificar os efeitos dos jogos lúdicos na iniciação do voleibol para crianças de 8 a 10 anos.

\section{MÉTODO}

Este trabalho foi realizado através de uma revisão de literatura, sendo um processo de busca, análise e descrição, por meio de pesquisas em artigos científicos, teses, livros, entre outras. Foram utilizadas as seguintes bases de dados: Scielo, Lilacs, Bireme, SBU Unicamp, Sportdiscus e livros publicados, junto delas, as seguintes palavras chave: pedagogia do esporte, voleibol e iniciação esportiva. Para essa afirmação, o quadro 1 representa a pesquisa dos artigos que foram encontrados no total, e somente alguns utilizados para elaboração deste trabalho.

Quadro 1: Quadro referente aos artigos encontrados e utilizados neste trabalho, em cada base de dados respectivamente.

\begin{tabular}{|c|c|c|c|c|c|c|c|c|c|c|}
\hline 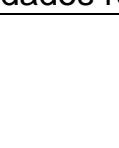 & \multicolumn{2}{|c|}{$\begin{array}{c}\text { Pedagogia do } \\
\text { esporte }\end{array}$} & \multicolumn{2}{|c|}{ Voleibol } & \multicolumn{2}{|c|}{$\begin{array}{l}\text { Iniciação } \\
\text { esportiva }\end{array}$} & \multicolumn{2}{|c|}{ Ludicidade } & \multicolumn{2}{|c|}{$\begin{array}{c}\text { Desenvolvimento } \\
\text { e habilidade } \\
\text { motora }\end{array}$} \\
\hline & Encont & Util & Encont & Util & Encont & Util & Encont & Util & Encont & Util \\
\hline LILACS & 90 & 1 & 30 & 0 & 373 & 0 & 43 & 1 & 56 & 0 \\
\hline BIREME & 30 & 1 & 25 & 0 & 249 & 0 & 50 & 0 & 30 & 0 \\
\hline LIVROS & 3 & 2 & 5 & 2 & 4 & 1 & 10 & 0 & 4 & 2 \\
\hline SBU & 130 & 1 & 0 & 0 & 270 & 0 & 300 & 0 & 25 & 0 \\
\hline SCIELO & 80 & 0 & 20 & 3 & 270 & 2 & 259 & 0 & 345 & 1 \\
\hline $\begin{array}{l}\text { SPORT } \\
\text { DISCUS }\end{array}$ & 30 & 0 & 0 & 0 & 301 & 0 & 58 & 0 & 0 & 0 \\
\hline
\end{tabular}

Encont $=$ Encontrados; Util= Utilizados. 
RESULTADOS E DISCUSSÃO

\section{CARACTERIZANDO A FASE DE 8 A 10 ANOS DA CRIANÇA}

Característica da criança de 8 a 10 anos

Segundo Piaget (2003) apud Ferracioli

(2007), a criança nesta idade consegue abstrair dados da realidade e também começa a desenvolver a capacidade de trajetos mentais, voltando ao ponto inicial de uma situação. Isso facilita no ensino do esporte, principalmente usando a lógica para problemas mais complexos, pensamentos prélógicos, para solução de problemas concretos e, no entanto, certa dificuldade em lidar com problemas não concretos.

Nesta faixa etária, as crianças sofrem grandes mudanças e começam a uma série de transformações, onde tem uma facilidade maior de aprendizado, um aumento de coordenação motora e também das habilidades para distinguir fatos da ficção. Existe nessa idade um maior interesse em permanecer em grupo, sendo capazes de cooperar e tornam-se menos egocêntricas (RODRIGUES, 2011).

Fases do desenvolvimento motor e habilidades motoras

Gallahue e Ozmum (2005), afirmam desenvolvimento motor são alterações em todo ciclo da vida dos seres humanos, sendo um processo permanente, aonde vem sofrendo transformação intrauterina até a sua morte. Esse processo ocorre através da maturação do sistema nervoso central e ainda aos estímulos que a criança recebe com a interação ao ambiente. Os estímulos dados nas habilidades fundamentais como locomover, manipular objetos e estabilização, devem começar do simples ao complexo. Assim contribuindo para um amplo repertório motor e desenvolvimento das habilidades essenciais.

O desenvolvimento motor é dividido em quatro fases: reflexiva, rudimentar, fundamental e especializada.

De acordo com Alves (2014), as habilidades básicas são divididas em três: manipulativa, locomotora, estabilização. Tais habilidades são classificadas a seguir:

- Manipulativa: arremessar, agarrar, cabecear, chutar, lançar, quicar e rebater.

- Locomotoras: andar, correr, saltar, saltitar, escorregar, escalar, rolar-se e desviar.

- Estabilizadoras: flexionar equilibrase, estender, girar, posições invertidas.

\section{PRINCIPIOS DA APRENDIZAGEM ESPORTIVA \\ O esporte é um fenômeno social e} cultural, que acontece dentro das relações humanas. Sendo assim, importante no processo educacional, para que o esporte possa acolher aos requisitos educacionais, não deve exclusivamente desenvolver as capacidades físicas, mas também, desenvolver talentos esportivos, técnicas e táticas. Reverdito e Scaglia (2009), afirmam que a pratica esportiva envolve a formação do cidadão, construindo ferramentas necessárias para o aumento cultural e social, por meio de interação do sujeito com o meio no qual esta inserido.

\section{Princípios da pedagogia esportiva}

A pedagogia do esporte busca compreender o fenômeno esportivo e sua complexidade. Esse fenômeno acontece nas condições sociocultural sendo um patrimônio da humanidade. É devida ao crescente interesse da coletividade pelas práticas esportivas. A pedagogia facilita os problemas entre a teoria e a prática, tendo como objetivo compreender e entender o processo de ensino aprendizagem do conhecimento dos esportes. Abrange os problemas educacionais, através do que foi produzido pela humanidade ao longo da sua história (PAES e BALBINO, 2012).

A competição proposta ao ambiente infantil deve considerar a instabilidades emocionais dos mesmos. Proporcionando oportunidades de vivenciar novas emoções sem constrangimentos (GALATTI et al., 2008).

Galatti et al., (2008), afirmam que é relevante, no processo de iniciação esportiva, que 0 professor deve transformar o meio esportivo em um ambiente de reflexão e diálogo, facilitando assim a relação interpessoal. Contribuindo para que as crianças obtenham cooperação, respeito, solidariedade e companheirismo.

Neste sentido o esporte é uma ferramenta fundamental no processo pedagógico, retornando a sua origem. Nesse contexto pode haver alterações as regras, a fim de proporcionar a motivação e interesse ao esporte, concomitante a esse processo a alegria e o prazer de competir (REVERDITO e SCAGLIA, 2009).

\section{Benefícios do lúdico na aprendizagem esportiva}

O universo lúdico pode ser uma saída para que, as crianças vivenciem e explorem todo seu potencial de movimento, com uma prática prazerosa e alegre. De acordo com o conhecimento amplo da palavra lúdico, está 
ligada com os jogos, as brincadeiras e o mundo de fantasia da criança (MELO et al., 2010).

O lúdico deve ser um ponto de partida ao iniciar a criança no esporte, sendo assim adequando o esporte a criança, elaborando procedimentos pedagógicos de acordo com sua necessidade (GALATTI et al., 2008).

Os jogos e brincadeiras desenvolvem a criança consciência corporais, favorece 0 desenvolvimento cognitivo, afetivo motor e interações sociais. E vai além desses aspectos, desenvolvem também a criatividade da criança, adquire a capacidade de lidar com conflitos e desafios. Os jogos não servem apenas como divertimentos, mas para que as crianças se torne um adulto criativo, com boa coordenação motora, saiba respeitar regras e ter boa relação interpessoal (SOUZA e JUNIOR, 2010).

\section{METODOLOGIA NO ENSINO DO VOLEIBOL}

O processo pedagógico para ensino do voleibol é necessário primeiramente conhecer suas características, regras e fundamentos do esporte. Sabendo que é um desporto praticado em uma quadra, dividindo as equipes em dois lados com uma rede entre eles.

\section{Contexto histórico do voleibol}

O voleibol foi criado, em 1895, de uma adaptação por William G. Morgan, diretor de educação física da Associação Cristã de Moços (ACM), na cidade de Holyoke, em Massachusets, nos Estados Unidos, pois seus alunos mais velhos adquiriram lesões ao jogarem basquetebol, devido ao alto grau de impacto do esporte, acarretando a afastamento da prática de atividade física (MEZZAROBA e PIRES, 2012).

Morgan inspirou-se a nova modalidade do tênis, na qual os jogadores foram separados por uma rede, onde a bola era enviada por cima da rede para o campo do adversário. Proporcionando grandes esforços físicos de pouco contato corporal (MEZZAROBA e PIRES, 2012).

O nome dessa modalidade esportiva era "minonette", que mais tarde renomearam de volleyball (volley $=$ voleio em inglês) devido o constante voleio da bola sobre a rede. E assim originando 0 voleibol da atualidade (BOJIKIAN e BOJIKIAN, 2008).

A bola de voleibol primitiva utilizou a mesma de basquetebol, na qual era inapropriada por causa do peso. Testando então sua câmera, que novamente não obteve sucesso, pois a mesma era muito leve. Morgan resolveu confeccionar uma bola especificamente para o esporte (BOJIKIAN e BOJIKIAN, 2008).

\section{Voleibol no Brasil}

Há duas versões para a introdução do voleibol no Brasil, uma que ele foi exercitado, pela primeira vez, em 1915, no Colégio Marista de Pernambuco. Entretanto outros dizem que o mesmo foi introduzido por volta de 1916/1917, pela ACM de São Paulo (BOJIKIAN e BOJIKIAN, 2008).

O ginásio do Fluminense, no Rio de Janeiro, foi palco do primeiro campeonato SulAmericano de Voleibol, masculino e feminino que foi patrocinado pela Confederação Brasileira de Desportos, no período de 12 a 22 de setembro de 1951 que teve como campeão - Brasil, no masculino e no feminino. (MEZZAROBA e PIRES, 2012).

\section{Complexidade do voleibol}

O voleibol é uma modalidade de alta complexidade e imprevisibilidade, caracterizado por ser um esporte de rede, no qual, não se tem domínio da bola, sendo necessário rebatê-la. É indispensável que na fase de aprendizagem, exista uma necessidade de estimular todas as capacidades e habilidades motoras exigidas pelo voleibol, pois o mesmo é dependente de muitas capacidades coordenativas de adaptação, capacidade de estabilização, ritmo, reação e orientação (REGA et al,2009).

Porat et al., (2013), caracteriza o esporte coletivo de natureza complexa, com duplo sentido : oposição contra adversário e cooperação entre os companheiros, no caso do voleibol a movimentação da bola entre as equipes, em circulação ou trocas de passes . Os aspectos de imprevisibilidade necessitam que seus participantes tenham domínio das capacidades perspectivas e as capacidades cognitivas nas tomadas de decisão.

As ausências desses atributos podem afetar a qualidade e eficácia do movimento estabelecido ao esporte. Para isso é indispensável 0 treinamento para essas habilidades e promovendo aprendizagem. Segundo estudos realizados por Rega et al., (2009), o treino das capacidades coordenativas é muito importante para facilitar a aprendizagem das crianças nos movimentos específicos do voleibol.

O professor deve proporcionar a criança um viés de exercícios e jogos que aproxime dos gestos motores exigidos pelo voleibol com toda sua dinâmica. A pedagogia do esporte proporciona o desenvolvimento das capacidades coordenativas especificas do voleibol, porém deve respeitar a idade e os limites de cada criança. É interessante proporcionar a prática de diversas 
modalidades esportivas, assim beneficiando mais conhecimentos e capacidades ao seu repertório motor (COLIN, 2015).

\section{Jogos e brincadeiras para a iniciação e} aprendizagem ao voleibol

O voleibol, deve ser base do princípio na aprendizagem de crianças entre 8 e 10 anos. Nas tarefas desportivas deve ser na qualidade do lúdico, interativo e agradável, a fim de oportunizar o ensino das práticas desportivas, proporcionando o entendimento tático (PAES e OLIVEIRA, 2004).

Ainda, segundo Paes e Oliveira (2004) em função da plasticidade do sistema nervoso central, as crianças encontram-se propensas a aprendizagem a partir de atividades que devem ser aplicadas sob vários ângulos: complexidade, variabilidade, diversidade e continuidade durante 0 procedimento de desenvolvimento.

É fundamental que a criança se familiarize com os componentes que envolvem o voleibol, como a bola, quadra, rede, etc., mesmo que não seja capaz de jogar corretamente. A criança deve ter muito contato com a bola nas aulas, pois muitas vezes são detectadas dificuldades por falta desse contato, que pode ser um grande desestímulo para ela, causando na maioria das vezes a desistência no voleibol (COLIM, 2015).

O mini vôlei, por ser um jogo prédesportivo, é uma boa opção para utilizar na iniciação. Com 7 ou 8 anos de idade é quando a criança começa a combinar suas habilidades e seus movimentos. Essa idade também é considerada ideal para a aprendizagem da criança no voleibol, segundo estudos realizados por Maciel (2014).

\section{CONCLUSÃO}

O voleibol possui tarefas de caráter complexas, possuindo muitas variações e trocas de percepções em espaços limitados.
Não permite que seu praticante tenha o domínio da bola, tornando assim um esporte de alta complexidade. Sabendo que as técnicas do vôlei são habilidades motoras especificas $o$ qual deve ser treinada $e$ aperfeiçoada.

Para ter êxito na aprendizagem da modalidade em questão, é de fundamental importância que a criança conheça a correta mecânica do movimento. É imposta de habilidades de precisão, e com percepção e decisão para uma correta execução. Complementando essa afirmação é indispensável que a criança apresente um repertório motor muito bem desenvolvido, e que os jogos diante de suas características, também preservam a aprendizagem da técnica do jogo pelo jogo.

O professor deve adequar à criança diversas experiências esportivas, com variadas modalidades. Assim 0 sujeito desenvolve diversas habilidades tanto motoras quanto cognitivas. Permitindo assim que a criança faça sua própria escolha, e evitando o cansaço e a desistência.

Para finalizar, concluímos que a aprendizagem do voleibol a partir do jogo, mostra-se uma saída importante como possibilidade metodológica, pois, proporciona ao aluno as sensações contidas no jogo formal, e para criança que inicia neste esporte é imprescindível. A técnica, é trabalhada com objetivos específicos regidos por necessidades táticas do jogo, além de todos os benefícios biopsicossociais elencados acima, e diante disto, abre-se precedentes a partir deste trabalho para pesquisas de campo, para elucidar questionamentos referentes aos jogos na aprendizagem das habilidades de rebater contidas neste trabalho. 


\section{REFERÊNCIAS}

ALVES, F. A. A Influência De Experiências Anteriores Na Aprendizagem De Novas Habilidades Motoras. Lume UFRGS, 2014.

BOJIKIAN, J.C.M., e BOJIKIAN,L.P. Ensinando voleibol.4 ed. Phorte Editora, São Paulo: 2008.

COLIM, C. M. O jogar/brincar para o aprendizado do voleibol. Monografia para Licenciatura em Educação Física-UFMS - UNIVERSIDADE FEDERAL DE MATO GROSSO DO SUL, Cuiabá, 2015.

FERRACIOLI, L. Aprendizagem, desenvolvimento e conhecimento na obra de Jean Piaget: uma análise do processo de ensino-aprendizagem em Ciências. Revista Brasileira de Estudos Pedagógicos, v. 80, n. 194, 2007.

GALATTI, L. R.; FERREIRA, H. B.; SILVA, Y. P. G.; PAES, R. R. Pedagogia do esporte: procedimentos pedagógicos aplicados aos jogos esportivos coletivos. CONEXÕES: Revista da Faculdade de Educação Física da UNICAMP, Campinas v. 6, ed. Especial, p. 397- 408, jul. 2008.

GALLAHUE, D. L.; OZMUN, J. C. Compreendendo o desenvolvimento motor: bebês, crianças, adolescentes e adultos. São Paulo: 3ed p.3-65, 2005.

MACIEL, R. N. Mini-voleibol como estratégia de ensino do voleibol. Perspectivas On Line, v. 5, n. 17, 2014.

MELO, J. P.; DIAS, N.; SOUZA, J. C. N. Do jogo e do lúdico no ensino da educação escolar. LICERERevista do Programa de Pós-graduação Interdisciplinar em Estudos do Lazer, v. 13, n. 1, 2010.

MEZZAROBA, C.; PIRES, G.L. Breve panorama histórico do voleibol: do seu surgimento à espetacularização esportiva. ATIVIDADE FíSICA, LAZER \&QUALIDADE DE VIDA: REVISTA DE EDUCAÇÃO FísICA, v. 2, n. 2, p. 3-19, 2012.

MÜLLER, A. J. Voleibol: desenvolvimento de jogadores. Florianópolis: Visual Books, 2009.

PAES, R. R; BALBINO, H. F. Pedagogia Do Esporte: Contextos e Perspectivas. Guanabara Koogan: Rio de Janeiro, 2012.

PAES, R. R.; OLIVEIRA, V. de. A pedagogia da iniciação esportiva: um estudo sobre o ensino dos Jogos desportivos coletivos. EFDeportes.com, Revista Digital Buenos Aires, № 71- Abril, 2004.

PORATH, M.N.; Milistetd, M.; Collet, C. N. S., R. T Nível de desempenho técnico-tático e experiência esportiva dos atletas de voleibol das categorias de formação. Revista educação física, v. 23, n. 4, p. 565-574, 2012.

REGA, G. C.; SOARES, T. A. A.; BOJIKIAN, J. C. M. Desenvolvimento das capacidades coordenativas no voleibol. Revista Mackenzie de Educação Física e Esporte, v. 7, n. 3, 2009.

REVERDITO, R.S; SCLAGIA, A. J. Pedagogia do esporte: jogos coletivos de invasão. São Paulo: Phorte, 2009

RODRIGUES, N. DOS R. "Desempenho motor e escolar em crianças de 6 a 10 anos: um estudo associativo". Lume UFRS, 2011.

SOUZA, R.N.; JÚNIOR, E.F. A influência da educação física moral do aluno. Efdportes Revista Digital Buenos Aires- Ano 15- N147-p.1. 2010. 